\title{
Perceptual-motor contributors to the association between developmental coordination disorder and academic performance: North-West Child Health, Integrated with Learning and Development study
}

\begin{tabular}{|c|c|}
\hline $\begin{array}{l}\text { Authors: } \\
\text { Elna de Waal }{ }^{1} \\
\text { Anita E. Piena } \\
\text { Dané Coetzee }\end{array}$ & $\begin{array}{l}\text { (1) } \\
\operatorname{ar}^{1} \\
0\end{array}$ \\
\hline $\begin{array}{l}\text { Affiliations: } \\
{ }^{1} \text { School of Hur } \\
\text { Sciences, Nor } \\
\text { University, So }\end{array}$ & $\begin{array}{l}\text { nan Movement } \\
\text { h-West } \\
\text { th Africa }\end{array}$ \\
\hline $\begin{array}{l}\text { Correspondin } \\
\text { Elna de Waal, } \\
\text { dewaale@ufs }\end{array}$ & $\begin{array}{l}\text { g author: } \\
\text { ac.za }\end{array}$ \\
\hline $\begin{array}{l}\text { Dates: } \\
\text { Received: } 28 \text { J } \\
\text { Accepted: } 15 \\
\text { Published: } 20\end{array}$ & $\begin{array}{l}\text { uly } 2017 \\
\text { Apr. } 2018 \\
\text { Sept. } 2018\end{array}$ \\
\hline $\begin{array}{l}\text { How to cite th } \\
\text { De Waal, E., P } \\
\text { \& Coetzee, D., } \\
\text { 'Perceptual-m } \\
\text { contributors t } \\
\text { association be } \\
\text { developmenta } \\
\text { disorder and } \\
\text { performance: } \\
\text { Child Health, } \\
\text { Learning and } \\
\text { study', South } \\
\text { of Childhood } \\
\text { a562. https:// } \\
\text { 10.4102/sajce }\end{array}$ & $\begin{array}{l}\text { is article: } \\
\text { ienaar, A.E. } \\
2018 \text {, } \\
\text { otor } \\
\text { o the } \\
\text { tween } \\
\text { I coordination } \\
\text { cademic } \\
\text { North-West } \\
\text { ntegrated with } \\
\text { Development } \\
\text { African Journal } \\
\text { iducation 8(2), } \\
\text { doi.org/ } \\
\text { v8i2.562 }\end{array}$ \\
\hline $\begin{array}{l}\text { Copyright: } \\
\text { (C) 2018. The } \\
\text { Licensee: AOS } \\
\text { is licensed un } \\
\text { Creative Comr } \\
\text { Attribution Lic }\end{array}$ & $\begin{array}{l}\text { uthors. } \\
\text { IS. This work } \\
\text { der the } \\
\text { nons } \\
\text { ense. }\end{array}$ \\
\hline Read online: & \\
\hline 回舟回 & $\begin{array}{l}\text { Scan this QR } \\
\text { code with your } \\
\text { smart phone or } \\
\text { mobile device } \\
\text { to read online. }\end{array}$ \\
\hline
\end{tabular}

Background: Children with developmental coordination disorder (DCD) portray motor coordination and perceptual difficulties which can hamper daily activity and academic task execution.

Aim: This study examined the association between DCD and academic performance, and explored which perceptual and motor coordination skills had the largest contribution to academic performance.

Setting: Ten-year-old children $(N=221,10.05$ years +0.41 standard deviation $)$ who formed part of the North-West Child Health, Integrated with Learning and Development (NW-CHILD) longitudinal study in South Africa were randomly selected to participate.

Methods: Motor coordination, visual-motor integration and academic achievement were assessed using the Movement Assessment Battery for Children-2, the Beery-Buktenica Developmental Test of Visual-Motor Integration-4, and national and mid-year assesments respectively. Spearman Rank order correlations and stepwise regression analyses were used to respectively determine significant associations and unique contributors.

Results: All perceptual and coordination skills differed between children with and without DCD, although only visual perception and manual dexterity showed overall correlations with academic performance in children with DCD. Visual perception also correlated strongly with maths $(r=0.26)$ and with the grade point average $(r=0.31)$ in children with and without DCD $(r=0.33, r=0.45)$. The highest contribution to the total variance $(23.11 \%)$ in math performance was explained by visual perception $(22.04 \%$ ), while visual perception contributed to $16.36 \%$ of $18.17 \%$ in the grade point average.

Conclusion: Children with DCD display significantly inferior visual-perceptual and coordination skills of which visual perception and manual dexterity influence academic performance (especially maths), negatively.

\section{Introduction}

Developmental coordination disorder (DCD) is characterised by deficits in the acquisition and execution of motor skills that can be identified at a young age and which has a negative impact on academic achievement and everyday activities (American Psychiatric Association [APA], 2013). DCD can only be diagnosed in the absence of any other neurological or intellectual disabilities (APA 2013). DCD is reported in 5\% - 6\% of 5- to 11-year-old children (APA 2013), with boys more likely than girls to have this condition (Asonitou et al. 2012; Lingam et al. 2009).

Several researchers report a link between motor problems and academic skills (Alloway \& Temple 2007; Schoemaker et al. 2001; Sortor \& Kulp 2003; Westendorp et al. 2011). Some explanations for this occurrence are given from a neuropsychological perspective. Motor and cognitive functions are coupled, because they use the same brain structures (Diamond 2000; Westendorp et al. 2011). Furthermore, Diamond (2000:49) reports that the cerebellum is involved in both motor and cognitive functions, while the prefrontal cortex plays an important role in motor and cognitive functioning as well as through the strong neural connections between these two brain areas. Dysfunction in any of these brain structures or neural pathways may therefore express itself in 
motor problems as well as in cognitive problems. A second argument is that motor and cognitive development follows the same timetable with an accelerated development between 5 and 10 years. If any dysfunction may occur in these brain structures, it could possibly lead to motor and cognitive problems. Furthermore, motor and cognitive functions share several common underlining processes, for example sequencing (Hartman et al. 2010; Westendorp et al. 2011), and monitoring and planning (Roebers \& Kauer 2009; Westendorp et al. 2011) which might also account for the co-occurrence of these problems.

Academic problems in children with DCD are associated with visual integration skills (Bonifacci 2004), visual functioning (Coetzee \& Pienaar 2011; Goldstand, Koslowe \& Parush 2005), visual processing skills (Goldstand et al. 2005) and convergence skills (Morad et al. 2002). Pienaar, Barhorst and Twisk (2013:377) report that the mastering of mathematics in South African Grade 1 learners depends on visual-perceptual skills where good visual-motor skills, visuospatial orientation and visual discrimination are required for the successful mastering of the foundational mathematical concepts. Movement execution depends on the ability to detect and analyse visual information (vision) received from the eyes (Botha 2013). Visual perception and motor coordination are part of an umbrella term, namely visual-motor integration skills (Beery \& Buktenica 1997) which is described as the ability to integrate visualperceptual skills with fine motor coordination (Beery \& Buktenica 1997; Cheatum \& Hammond 2000). Motor coordination influences the effective co-operation of body parts to produce smooth body movement, while visual perception (Schoemaker et al. 2001) is an acquired process by which useful visual information is obtained through effective conversion of images (Bezrukikh \& Terebova 2009; Cheatum \& Hammond 2000).

Children with DCD's visual-motor perception and spatial orientation are described as inhibited and their ability to make quick motor adjustments are hence affected (APA 2013). Purcell et al. (2012:304) are of the opinion that the ability of children with DCD to process movement demands is influenced by poor visual-motor integration skills. Wellplanned, coordinated and conscious movement can only take place when strength control is applied correctly, when motor planning occurs in fine detail and when continuous adjustments are made correctly by the neurological feedback system (Botha 2013). Clarification of different subsystems, including sensory and perceptual systems that contribute to general coordination, development of motor coordination and motor coordination difficulties is therefore of importance when assessing DCD (Cermak \& Larkin 2002). A variety of test components can be required to approach the general construct of coordination, including tasks measuring neurodevelopmental function, tasks classified on the basis of interaction with the environment and fine and gross motor tasks (Cermak \& Larkin 2002). Researchers (Dwyer, Baur \& Hardy 2009; Riethmuller, Jones \& Okely 2009) highlight in this regard that many body systems, including sensory, musculoskeletal and neurological systems are being incorporated during a child's motor skill development and are therefore different but important underlying constructs of coordinated performance in children.

Gross motor skills are highlighted by various researchers as an important contributor to later cognitive achievement (Lopes et al. 2013; Piek et al. 2008; Son \& Meisels 2006). Skills, generally executed in the classroom such as copying activities and skills that must be performed at speed, appear to be weaker in children with poor motor coordination because of slower inhibition of dominant responses (Michel et al. 2011). Proper muscle functioning also influences writing tasks such as quality of handwriting and writing speed (Malloy-Miller, Polatajko \& Anstett 1995; Schwellnus et al. 2012). Perceptualmotor skills also have an influence on various scholastic tasks where spatial orientation, for example, is important for a clear understanding of number lines (Gunderson et al. 2012) and plays an important role in general mathematical abilities (Van Lill 2011). Perceptual skills are reported to have the greatest impact in the earlier school years or more importantly contribute to the earlier stages of mathematics (Geary, Hamson \& Hoard 2000).

Relationships between DCD and visual-motor integration skills (Bonifacci 2004; Cheng et al. 2014; Tsai, Wilson \& Wu 2008), and between academic achievement and visual-motor integration skills are also reported (Goldstand et al. 2005; Kulp 1999; Pieters et al. 2012; Van Hartingsveldt et al. 2014). The findings reported by Alloway and Temple (2007:483) indicate that children with DCD display deficiencies with regard to working memory; thus implying that these children's literacy and numeracy skills will be influenced negatively. Children with DCD have poor executive functioning abilities (Zhu, Tang \& Shi 2012) which can negatively impact their motor development (Leonard et al. 2015; Schurink et al. 2012) and academic achievement (Thorell et al. 2013). Handwriting speed depends on the maturity of visual-motor integration as well as visual information processing and memory (Tseng \& Chow 2000). The mastering of visual-motor abilities (Memisevic \& Sinanovic 2013), visual working memory (Lepach, Pauls \& Petermann 2015) and motor skills (Schurink et al. 2012:730) relies on effective executive functioning.

Thus, it appears from research findings that motor deficits in children with DCD based on different subsystems such as sensory, perceptual and neurodevelopmental function that contribute to the construct of general coordination, would impact negatively on their academic achievement. Research by Carlson, Rowe and Curby (2013:527) also indicates that visual-spatial integration keeps on developing and plays an important role in academic achievement. A lack of knowledge was identified from the literature, as no South African studies were found regarding this possible relationship which necessitates further research in this regard, especially on South African children. The objective of this study is therefore 
to determine whether an association exists between visual perception, motor coordination and visual-motor integration skills and academic achievement in 10-year-old children with DCD, and which of these perceptual and motor coordination skills have the largest contribution to academic performance.

\section{Method \\ Study design}

This study was based on a cross-sectional cohort that was part of a stratified and randomised longitudinal study design (NW-Child Health, Integrated with Learning and Development), which covered a period of 6 years (2010 2016). The North-West Child Health, Integrated with learning and Development (NW-CHILD) study included baseline measurements and two follow-up test opportunities during this period (2013-2016). In order to determine the sample for the baseline measurements in 2010, a list of schools in the North West Province was obtained from the Department of Basic Education (DoBE), where after stratification was done according to school regions and school types (quintile 1-5). A list of schools in the North West Province, which were grouped into eight education districts that each represented 12-22 regions, each with approximately (minimum 12, maximum 47), were used. Four regions and were then randomly selected with regard to population density and school status. Within each region, five schools were selected where each of these schools represented the particular quintiles (Quintile 1 - schools in poor economic areas to Quintile 5 - schools in good economic areas). The DoBE in each province used a poverty classification to classify schools in different quintiles. This poverty classification was obtained from the National Census data which included income, dependant ratios and levels of literacy (Pauw 2005). Quintile 1-3 schools represented children from low socio-economic environments where Quintile 1 and 2 schools are released from paying school fees, while Quintile 4-5 schools represented learners from higher socio-economic schools (Pauw 2005).

\section{Study population}

Participants from five schools in one of the four school districts, who were part of the 2013 first follow-up measurements of the NW-CHILD study, formed part of the study. Boys and girls who were part of the 2010 study in their Grade 1 year were again tested during their Grade 4 year (in some cases in their Grade 3-year because of retention). The group included 221 Grades $3(n=55)$ and four participants $(n=166)$ who were part of the Zeerust district. The mean age for this group was 10.05 years, with a standard deviation (SD) of 0.41 and minimum and maximum age values of 8.65 years and 10.64 years, respectively. The population included participants from different quintile schools (Quintile 1 [ $n=48]$; Quintile 2 [ $n=44]$; Quintile $3[n=48]$; Quintile $4[n=31]$ and Quintile $5[n=50]$ ) and represented a reasonable distribution of the South African population with $84.16 \%(n=196)$ of the participants being black South Africans, $11.76 \%(n=26)$ white South Africans and $4.07 \%(n=9)$ from other ethnic groups. The Movement Assessment Battery for Children, second edition (MABC-2) was used as the measuring instrument for the study to determine DCD, and all DSM-5 criteria were applied in identifying the DCD group. Children were identified with moderate- to severe-DCD when they fell below the 16th percentile after completing the MABC-2 test and if they experienced learning related problems as indicated in the second DSM- 5 criteria (APA 2013). If a child fell below the 16th percentile (MABC- 2 test) and obtained less than $39 \%$ in two or more of the six compulsive academic learning areas, they were hence included in the DCD group. Children with serious neurological or intellectual disability were excluded using information obtained from the schools.

\section{Data collection}

\section{Movement Assessment Battery for Children, second edition}

The MABC-2 is a test battery that focuses on the identification of impaired motor function in children between the ages of 3 and 16 (Henderson, Sugden \& Barnett 2007). This measurement instrument applies to three age groups, namely 3- to 6-year-olds, 7- to 10-year-olds and 11- to 16 -year-olds. For the purposes of this study, only the tests applicable to the age band that includes 7- to 10-year-old age children were used. Within each age group, eight subitems were divided into the following three coordination subsections: manual dexterity, aiming-and-catching and balance. The manual dexterity subtest consisted of three sub-items, while there were two aiming-and-catching subitems and three balance sub-items. Each activity was demonstrated by the test recorder prior to a trial effort and two formal test efforts. The second test effort was only executed if the participant failed the first attempt or if the activity was not executed within the specific time limit set for his or her age group on the record form. It took between 20 and $40 \mathrm{~min}$ to complete the test. Each sub-item's raw score was converted to an item standard score. These item standard scores were then added up to obtain an overall standard score and percentile for each subdivision. Finally, the total test score (sum of all eight items' standard scores) was converted to an overall standard score and percentile. A higher standard score indicated a better overall performance. The overall test percentile was categorised according to different DCD statuses. Participants with percentiles at or below five or between the 5th and 16th percentile were grouped into the moderate- to severe-DCD group. Any values at or above the 16th percentile placed a participant in the typical or without-DCD category. The total test scores that classified participants in different DCD categories were as follows: a test score of less than or equal 67 indicated moderate to severe-DCD, while a score of more than 67 placed the participant in the typical or withoutDCD category. The MABC-2 is a valid test to reliably identify children with and without motor deficits. Reported validity values ranged between $r=0.84$ (Tan, Parker \& Larkin 2001) and $r=0.6$ to $r=0.9$ (Croce, Horvat \& McCarthy 2001). 


\section{Beery-Buktenica Developmental Test of Visual-Motor Integration, 4th edition}

The Beery-Buktenica Developmental Test of Visual-Motor Integration, 4th edition (VMI-4), is a measurement instrument that assesses visual-motor integration skills and consists of two additional subtests, namely visual perception and motor coordination (Beery \& Buktenica 1997). The two additional tests focus on visual perception and motor coordination where the latter shave a particular focus on hand control. The purpose of the VMI-4 is the early identification of children with impaired visual-motor integration (VMI) as well as determining the extent to which an individual's visual and motor abilities can be integrated. The extent of the concurrence between visual perception and fine motor movement is included in this measuring instrument. Poor results in the VMI- 4 can be ascribed to the inability to integrate visualperceptual (VP) and motor skills and not necessarily to insufficient skills. The VMI-4 is a reliable test battery with a validity of $r=0.92, r=0.91$ and $r=0.89$. The VMI test consisted of drawing three trial shapes and 24 increasingly complex geometric shapes. Each participant was expected to draw a geometric shape with a pencil (without using an eraser) and only one attempt per shape was allowed. This test had to be completed within the set time or was stopped after three consecutive mistakes. It took approximately 10-15 $\mathrm{min}$ to complete and could be executed individually or in a group. The visual-perceptual (VMI-VP) additional test required each participant to identify the correct corresponding shape of each item in a series of 27 geometric shapes. This test was executed individually. It took three minutes to complete the test and the test was stopped after 3 minutes or after three consecutive mistakes were made. The motor coordination (VMI-MC) additional test required the copying of a geometric shape during which the participant must have drawn it as correctly as possible while remaining within the given lines. This test could be executed in a group or individually and the execution was stopped after 5 minutes had passed. The criteria for the allocation of points in the VMI- 4 were as follows: A ' 0 ' was allocated for incorrect figures and a ' 1 ' for correct figures. The test was stopped when the time has elapsed or after three consecutive mistakes were made, except in the MC subtest, which was only stopped after the allocated time had elapsed. Data in this test were collected consecutively in three categories in the following order: VMI, visual perception and motor coordination. The raw scores were converted to standard scores and thereafter to percentile values. The standard scores were used to divide the participants into five different categories, ranging from very low (40-67), below average (68-82), average (83-117), above average (118-132) to very high (133-160) (Beery \& Buktenica 1997).

\section{Academic achievement}

Academic school grading progress reports of the June midyear assessments reflected the grading code of each of the six required learning areas of the particular participants in Grades 3 and 4 as well as the grade point average score of the six learning areas were obtained from each of the participating schools in 2013. The six compulsory learning areas were stipulated in the DoBE's South Africa Curriculum and Assessment Policy Statement (2014) and include the following learning areas: mathematics, home language, second language, natural sciences (NS), social sciences (SC) and life orientation (LO). Language learning in Grade 4 included all the official languages in South Africa, namely Afrikaans, English, isiNdebele, isiXhosa, isiZulu, Sepedi, Sesotho, Setswana, SiSwati, Tshivenda and Xitsonga. Home language referred to one or two languages offered at home language level (for the applicable school or district), while second language referred to a language which is not a mother tongue, but which is used for certain communicative functions in a society or in the classroom (CAPS 2014). National assessment guidelines for the Annual National Assessment (ANA), which is written in September of each year and which is compiled at a national level and written by all South African learners in maths and language skills as a requirement of the DoBE (DE 2016), required that learners had to be evaluated in the ANA assessment on knowledge that had to be assimilated during the first three quarters of the school year from January to December. These ANA results of each participant were also made available by the Department of Basic Education (2014) of the North West Province for each participating school. Academic performance in each learning area was coded into categories according to official grading codes in the CAPS which were then expressed as follows: A ' 7 ' is allocated for exceptional achievement ( $80 \%-100 \%)$; a ' 6 ' for meritorious achievement (70\% - 79\%); a ' 5 ' for considerable achievement $(60 \%-69 \%)$; a ' 4 ' for sufficient achievement $(50 \%-59 \%)$; a ' 3 ' for average achievement $(40 \%-49 \%)$; a ' 2 ' for basic achievement $(30 \%-39 \%)$; and $a$ ' ' 1 ' is allocated when the learning outcome was 'not achieved' (0\% - 29\%). The June mid-year assessments were compiled and scored by the applicable teachers where the ANA tests were compiled nationally by the DoBE but marked by the teachers therefore making it a more objective, representative and comparative assessment of learners' academic achievements.

\section{Data analysis}

The Statistica for Windows 2015 (StatSoft 2015) was used to analyse the data. The data were analysed descriptively by using means (M), SD and minimum and maximum values (StatSoft 2015). Bivariate Spearman Rank order correlation coefficients $(r)$ were used to analyse correlations and the following guidelines were used to determine the strength of significant associations in practice: $r \approx 0.1$ indicated a small practical significance, $r \approx 0.3$ a moderate significance and $r \geq$ 0.5 a large practical significance (Cohen 1988). In addition, a stepwise regression analysis was performed for exploratory purposes to determine the predictor variables that showed the largest unique contribution to the total variance in academic performance. Academic achievement in six learning areas as well as the grade point average of these six learning areas were used as the outcome variables in the regression analysis, while different constructs, which 
influence general coordination such as perceptual-motor abilities (VMI, visual perception and motor coordination) and motor coordination functioning (manual dexterity, aiming-and-catching and stability), were used as the predictor variables. Two regression analyses were performed: one on the performance in learning areas that were assessed nationally and another one on the academic performance during the mid-year school assessments.

\section{Ethical consideration}

Ethical approval (based on the Helsinki guidelines) for the execution of the NW-CHILD study was obtained from the Ethics Committee of the North-West University (No. NW00070-09-A1). Permission was also obtained from the Department of Basic Education of the North West Province, South Africa. Principals of the various identified schools also had to provide permission for the collection of data during school hours. The parents and/or legal guardians of all the Grade 3 and 4 participants who participated in the study had to provide parental permission for them to participate in the study. Data were collected by the senior researchers and postgraduate students with qualifications in Human Movement Sciences, specialising in Kinderkinetics. If a participant's mother tongue was not English or Afrikaans, trained interpreters were used to explain the test instructions to the participant

\section{Results}

Descriptive and demographic information of the group can be found in Tables 1 and 2. DCD was identified in 47 (21.27\%; 23 boys and 24 girls) of the 221 participants of which 14 (6.33\%; seven boys and seven girls) were classified with severe-DCD (at or below the 5 th percentile). One hundred and seventy-four participants $(78.73 \%)$ fell above the 16 th percentile, showing no signs of DCD and will serve as the reference group referred to as a group without-DCD or typical children. Table 2 reports the number of participants per learning area as well as their academic achievements during the June mid-year school assessment and the September ANA.
Table 3 reports descriptive values of the group as well as significant differences between the DCD group $(<16$ th percentile) and the without-DCD group as obtained in each of the outcome variables which included all the subsections of the VMI- 4 and the MABC-2. The mean values in the DCD group were poorer in each of these subsections of both the VMI-4 and the MABC-2, compared to those in the withoutDCD group. Statistical $(p \leq 0.05)$ and medium to large practical $(d \geq 0.8)$ significant differences are found for all the VMI-4 and MABC-2 variables. The visual perception mean standard score (79.17) of the DCD group is also categorised as below average (68-82), compared to the visual perception of the without-DCD group (84.57) that fell in the average category (83-117) (Beery \& Buktenica 1997) which have clinical relevance.

Relationships were further analysed with Spearman Rank order correlations (Table 4 ) between the three VMI-4 variables (VMI, visual perception and motor coordination), the three MABC-2 variables (manual dexterity, object manipulation and balance) as well as the academic achievements obtained in the

TABLE 1: Descriptive statistics of the group $(N=221)$.

\begin{tabular}{llcc}
\hline Variable & Subdivision & $\boldsymbol{N}$ & $\mathbf{\%}$ \\
\hline Gender & Boys & 123 & 55.66 \\
& Girls & 98 & 44.34 \\
Race & white South Africans & 26 & 11.76 \\
& black South Africans & 186 & 84.16 \\
& Other & 9 & 4.07 \\
Quintile & Quintile 1 & 48 & 21.72 \\
& Quintile 2 & 44 & 19.91 \\
& Quintile 3 & 48 & 21.72 \\
& Quintile 4 & 31 & 14.03 \\
& Quintile 5 & 50 & 22.62 \\
DCD classification & Severe-DCD group & 14 & 6.34 \\
& Moderate-DCD group & 33 & 14.93 \\
Gender within the & Without-DCD group & 174 & 78.73 \\
moderate- and & Boys & 23 & 48.94 \\
severe-DCD groups & & 24 & 51.06 \\
\hline Total & Girls & $\mathbf{2 2 1}$ & $\mathbf{1 0 0 . 0 0}$ \\
\hline
\end{tabular}

$N$, number of participants, \%, percentage; DCD, developmental coordination disorder.

TABLE 2: Academic marks during the June mid-year assessment and the Annual National Assessment.

\begin{tabular}{|c|c|c|c|c|c|}
\hline \multirow{2}{*}{$\begin{array}{l}\text { Learning area } \\
\text { June } 2013\end{array}$} & \multirow{2}{*}{$\begin{array}{c}\text { Number of participants } \\
N\end{array}$} & \multicolumn{4}{|c|}{ Percentage } \\
\hline & & M & SD & Min & Max \\
\hline \multicolumn{6}{|c|}{ June mid-year assessment } \\
\hline Afrikaans & 79 & 64.27 & 12.85 & 25.0 & 94.0 \\
\hline Setswana & 137 & 49.96 & 19.54 & 7.0 & 86.0 \\
\hline English & 216 & 53.34 & 22.09 & 5.0 & 96.0 \\
\hline Mathematics & 216 & 61.99 & 15.16 & 2.0 & 96.0 \\
\hline Social sciences & 166 & 56.78 & 19.95 & 6.0 & 98.0 \\
\hline Natural sciences & 166 & 56.95 & 20.07 & 4.0 & 96.0 \\
\hline Grade point average & 216 & 55.57 & 16.91 & 14.5 & 91.67 \\
\hline \multicolumn{6}{|l|}{ ANA 2013} \\
\hline Afrikaans & 49 & 68.69 & 17.03 & 8.0 & 90.0 \\
\hline Setswana & 54 & 24.81 & 19.35 & 0.0 & 82.0 \\
\hline English & 111 & 53.28 & 20.54 & 4.0 & 96.0 \\
\hline
\end{tabular}

$N$, number of participants; M, mean values; SD, standard deviation; Min, minimum values; Max, maximum values; ANA, Annual National Assessment. 
TABLE 3: Descriptive statistics and significance of differences in the Visual-Motor Integration-4 score and Movement Assessment Battery for Children, second edition scores in the developmental coordination disorder (DCD) and without-DCD groups.

\begin{tabular}{|c|c|c|c|c|c|c|c|c|c|c|c|c|}
\hline \multirow[t]{2}{*}{ Test batteries } & \multirow[t]{2}{*}{ Subdivisions } & \multirow[t]{2}{*}{ M } & \multirow[t]{2}{*}{ SD } & \multirow[t]{2}{*}{ Min } & \multirow[t]{2}{*}{ Max } & \multicolumn{2}{|c|}{ DCD group $(N=47)$} & \multicolumn{3}{|c|}{ Without-DCD group $(N=174)$} & \multirow[t]{2}{*}{$p$ value } & \multirow[t]{2}{*}{$d$ value } \\
\hline & & & & & & $M$ & SD & $M$ & SD & $t$ value & & \\
\hline \multirow[t]{3}{*}{ VMI-4 (SS) } & VMI & 95.72 & 14.21 & 66.0 & 137.0 & 89.91 & 11.93 & 97.83 & 14.07 & 4.42 & $0.000 *$ & $0.70^{\# \#}$ \\
\hline & VP & 84.43 & 17.13 & 45.0 & 127.0 & 79.17 & 13.42 & 85.83 & 17.76 & 2.39 & $0.018^{*}$ & $0.38^{\#}$ \\
\hline & MC & 94.71 & 12.61 & 58.0 & 135.0 & 90.47 & 13.44 & 95.79 & 12.18 & 2.60 & $0.010 *$ & $0.40^{\#}$ \\
\hline \multirow[t]{4}{*}{ MABC-2 (SS) } & Dexterity & 7.84 & 2.56 & 2.0 & 15.0 & 4.66 & 1.68 & 8.70 & 2.02 & 12.54 & $0.000 *$ & 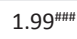 \\
\hline & $A-\&-C$ & 11.30 & 5.90 & 5.0 & 91.0 & 9.72 & 2.24 & 11.73 & 6.48 & 2.09 & $0.038 *$ & $0.31^{\#}$ \\
\hline & Balance & 10.90 & 3.08 & 2.0 & 15.0 & 7.79 & 2.38 & 11.80 & 2.58 & 10.24 & $0.000 *$ & $1.66^{\# \# \# ~}$ \\
\hline & Total & 9.51 & 2.51 & 2.0 & 15.0 & 5.96 & 1.28 & 10.47 & 1.80 & 16.10 & $0.000 *$ & $2.51^{\# \# \#}$ \\
\hline
\end{tabular}

DCD, developmental coordination disorder; SS, standard score; M, mean values; SD, standard deviation; VMI, visual-motor integration standard score; VP, visual perception standard score; MC motor coordination standard score; A-\&-C, aiming-and-catching; MABC-2, Movement Assessment Battery for Children, second edition standard score; VMI-4, Developmental Test of Visual-Motor Integration-4.

$*, \leq 0.05$.

$\#, d \geq 0.3 ; \#, d \geq 0.5 ; \#, d \geq 0.8$

TABLE 4: Spearman Rank order correlations between Visual-Motor Integration-4 and Movement Assessment Battery for Children, second edition variables and academic achievement in the June mid-year and the national (Annual National Assessment) assessments in children without developmental coordination disorder $(n=174)$.

\begin{tabular}{|c|c|c|c|c|c|c|c|c|c|c|c|c|c|}
\hline \multirow[t]{2}{*}{ Test batteries } & \multirow[t]{2}{*}{ Subdivisions } & \multicolumn{8}{|c|}{ Learning areas (June percentage) } & \multicolumn{4}{|c|}{ Learning areas (ANA percentage) } \\
\hline & & Afr. & Eng. & Tswana. & Math. & NS & LO & SS & GPA & Afr. & Eng. & Tswana. & Math. \\
\hline \multirow[t]{3}{*}{ VMI-4 (SS) } & Visual-motor integration & $0.25 *$ & 0.10 & 0.08 & 0.13 & 0.15 & 0.07 & 0.04 & 0.12 & 0.16 & $0.23 *$ & 0.12 & $0.18 *$ \\
\hline & Visual perception & 0.22 & $0.40 * *$ & $0.23 *$ & $0.33 * *$ & $0.43 * *$ & $0.46 * *$ & $0.23 *$ & $0.45 * *$ & $0.35 * *$ & $0.35 * *$ & 0.06 & $0.53 * * *$ \\
\hline & Motor coordination & $0.30 * *$ & $0.20 *$ & 0.17 & 0.15 & $0.17 *$ & 0.14 & 0.02 & $0.19 *$ & $0.31 * *$ & $0.29 *$ & 0.15 & $0.27 *$ \\
\hline \multirow[t]{4}{*}{ MABC-2 (SS) } & Manual dexterity & -0.03 & 0.13 & $0.21 \%$ & $0.18 *$ & 0.09 & 0.07 & 0.12 & 0.14 & 0.00 & -0.02 & $0.37 * *$ & 0.09 \\
\hline & Aiming-and-catching & 0.06 & 0.09 & 0.19 & $0.17 *$ & 0.06 & 0.12 & 0.04 & 0.14 & 0.17 & 0.17 & -0.01 & 0.11 \\
\hline & Balance & $0.31 * *$ & 0.09 & 0.04 & 0.12 & 0.16 & 0.13 & 0.06 & 0.14 & 0.17 & 0.11 & -0.11 & $0.20 *$ \\
\hline & MABC total & 0.18 & $0.20 *$ & $0.25 *$ & $0.26 *$ & $0.18^{*}$ & $0.16 *$ & 0.08 & $0.24 *$ & 0.28 & 0.13 & $0.32 * *$ & $0.26 *$ \\
\hline
\end{tabular}

SS, standard score; ANA, Annual National Assessment; Afr., Afrikaans; Eng., Engels; Tswana., Setswana; Math., Mathematics; NS, natural sciences; LO, life orientation; SS, social sciences; GPA, grade point average; MABC, Movement Assessment Battery for Children.

$*, r>0.1=$ small practical effect; $* *, r>0.3=$ medium practical effect; $* * *, r>0.5=$ large practical effect.

TABLE 5: Spearman Rank order correlations between Visual-Motor Integration-4 and Movement Assessment Battery for Children, second edition variables and academic achievement in the June mid-year and national (Annual National Assessment) assessments in children with moderate- to severe developmental coordination disorder (<16th percentile) $(n=47)$

\begin{tabular}{|c|c|c|c|c|c|c|c|c|c|c|c|c|c|}
\hline \multirow[t]{2}{*}{ Test batteries } & \multirow[t]{2}{*}{ Subdivisions } & \multicolumn{8}{|c|}{ Learning areas (June percentage) } & \multicolumn{4}{|c|}{ Learning areas (ANA percentage) } \\
\hline & & Afr. & Eng. & Tswana. & Math. & NS & LO & SS & GPA & Afr. & Eng. & Tswana. & Math. \\
\hline \multirow[t]{3}{*}{ VMI-4 (SS) } & Visual-motor integration & 0.32 & 0.06 & 0.08 & 0.16 & 0.11 & 0.08 & 0.15 & 0.17 & 1.00 & 0.31 & -0.31 & 0.01 \\
\hline & Visual perception & 0.48 & $0.32 * *$ & 0.12 & $0.26 *$ & $0.43 * *$ & $0.38 * *$ & 0.20 & $0.31 * *$ & 0.50 & 0.31 & 0.20 & 0.18 \\
\hline & Motor coordination & 0.12 & 0.01 & 0.22 & -0.00 & 0.10 & 0.24 & 0.15 & 0.09 & -0.50 & 0.15 & -0.25 & -0.03 \\
\hline \multirow[t]{4}{*}{ MABC-2 (SS) } & Manual Dexterity & 0.44 & $0.37 * *$ & 0.25 & $0.42 * *$ & 0.20 & $0.31 * *$ & $0.56 * * *$ & $0.42 * *$ & 0.50 & 0.26 & 0.33 & $0.39 * *$ \\
\hline & Aiming-and-Catching & -0.25 & -0.16 & -0.07 & -0.05 & -0.04 & 0.16 & $-0.43 * *$ & -0.10 & -0.87 & -0.06 & -0.19 & -0.10 \\
\hline & Balance & -0.36 & -0.13 & 0.27 & -0.26 & 0.04 & -0.15 & -0.18 & -0.15 & -0.50 & 0.03 & -0.01 & 0.10 \\
\hline & MABC Total & -0.32 & -0.05 & 0.27 & -0.10 & 0.03 & 0.06 & -0.10 & -0.03 & -0.87 & 0.03 & -0.13 & 0.08 \\
\hline
\end{tabular}

SS, standard score; ANA, Annual National Assessment; Afr., Afrikaans; Eng., Engels; Tswana., Setswana; Math., Mathematics; NS, natural sciences; LO, life orientation; SS, social sciences; GPA, grade point average; MABC2, Movement Assessment Battery for Children, second edition standard score; VMI-4, Developmental Test of Visual-Motor Integration-4; ANA, Annual National Assessment.

$*, r>0.1=$ small practical effect; $* *, r>0.3=$ medium practical effect; $* * *, r>0.5=$ large practical effect.

mid-year school assessment and the National assessment (ANA) in the without-DCD group $(n=174)$. Visual perception showed the strongest correlations with all the learning areas during the mid-year school assessments and also correlated the highest with the ANA results for Afrikaans, English and mathematics in the group. Motor coordination also reflected correlations, but showed only a small strength of association with most of the learning areas, while a relationship indicating moderate practical significance was established with Afrikaans $(r=0.32)$. Visual-motor integration reflected the smallest number of correlations with the different academic learning areas all of which indicated a small practical significance.

Table 5 displays a similar analysis for children with DCD $(n=47)$. Manual dexterity and visual perception, and the total MABC score showed clear relationships with most of the learning areas, indicating medium to strong effect sizes. The strongest correlations were found between manual dexterity and most of the learning areas. The highest relationships in both the june school $(r=0.42)$ and ANA $(r=0.39)$ assessments were found between maths and manual dexterity.

As these correlations indicated that the outcome variables are all related to academic performance in children with and withoutDCD, a forward step-by-step regression analysis was performed to determine the unique percentage variance explained contribution $\left(\Delta R^{2}\right)$ of best predictors for academic achievement in the group (Table 6). This analysis determined which of the three perceptual-motor constructs and the three motor coordination constructs had the biggest contribution to the variance that are explained in academic performance by these 
TABLE 6: Unique percentage variance explained contribution $\left(\Delta R^{2}\right)$ of best predictors for each learning area as given by a forward step-by-step regression analysis for the mid-year June school assessment and the Annual National Assessment.

\begin{tabular}{|c|c|c|c|c|c|c|c|}
\hline \multirow[t]{2}{*}{ Learning areas } & \multicolumn{6}{|c|}{ Contributors } & \multirow{2}{*}{$\begin{array}{l}\text { Total variance } \\
\text { explained \% }\end{array}$} \\
\hline & VP & MC & VMI & Balance & Manual dexterity & Aiming and catching & \\
\hline \multicolumn{8}{|c|}{ June mid-year school assessment } \\
\hline Afr. & 3.28 & 10.77 & - & 1.55 & - & - & 15.60 \\
\hline Eng. & 11.55 & - & - & 0.50 & 0.46 & - & 12.50 \\
\hline Tswana & 6.71 & 0.76 & - & - & 1.00 & - & 8.44 \\
\hline Math & 9.68 & - & - & 1.82 & - & - & 11.50 \\
\hline LO & 15.46 & 0.50 & 0.72 & - & - & 0.75 & 17.43 \\
\hline NS & 12.58 & 0.95 & - & - & - & - & 13.54 \\
\hline SS & 3.89 & - & - & 1.29 & 1.11 & - & 6.29 \\
\hline GPA & 16.36 & 0.42 & - & - & 0.95 & - & 18.17 \\
\hline \multicolumn{8}{|c|}{ Annual National Assessment } \\
\hline Afr. & 15.93 & 3.51 & 2.46 & - & - & - & 23.65 \\
\hline Eng. & 5.25 & 8.50 & - & - & - & - & 13.75 \\
\hline Tswana & 1.12 & - & 1.80 & 3.49 & - & - & 6.41 \\
\hline
\end{tabular}

Note: Bold values indicate the highest \% variance for each learning area.

Afr., Afrikaans; Eng., English; Tswana., Setswana; Math., Mathematics; LO, life orientation; NS, natural sciences; SS, social sciences; GPA, grade point average; VP, visual perception; MC, motor coordination; VMI, visual-motor integration.

variables. The results obtained for the six compulsory learning areas and the grade point average of these six learning areas in the mid-year June school assessment as well as the National assessment (ANA), which only assess mathematics, home language and first additional language, are both displayed in Table 6. Visual perception explained the largest unique contribution of the total variance of all six perceptual-motor and coordination predictor variables in both regression analyses (Table 6) with the exception in Afrikaans (June) and English (ANA) where motor coordination showed a higher contribution to the total variance. Visual perception had the highest unique contribution to the total variance in all the other learning areas as well as in the grade point average. A total percentage variance of $18.17 \%$ was explained by these predictor variables in the grade point average where $16.36 \%$ was contributed by visual perception, while motor coordination $(0.42 \%)$ and manual dexterity $(0.95 \%)$ made additional small contributions. The ANA results, which were based on standardised papers drawn up nationally where teachers' subjective influence could hence not play a role, are also displayed in Table 6. The contribution of visual perception was even higher in two of the learning areas that were assessed. In Mathematics, visual perception explained $22.04 \%$ of the total percentage variance of $23.11 \%$, while in Afrikaans visual perception contributed to $15.93 \%$ of the $23.65 \%$. Manual dexterity and balance also proved to be contributors, although very small percentages of the total percentage variance were explained by these predictor variables. It appeared from these results that visual perception rather than visual-motor integration served as a significant contributor to academic achievement.

\section{Discussion}

This study examined the association between DCD, perceptual and motor coordination skills and academic achievement in 10-year-old children, The results firstly confirmed an overall relationship between visual perception and academic achievement of children, irrespective of whether they had coordination problems (DCD) (Table 4), while moderate to strong correlations were also established between DCD, manual dexterity, visual perception and academic achievement (Table 5). The study also verified that of all the different perceptual and coordination constructs that were measured, visual perception had the highest correlation with mathematical achievement in typical children, emphasising the importance of this relationship in practice (Table 4). Kulp et al. (2004:161) confirmed similar relationships between visual perception and mathematical skills, specifically in activities that involved visual memory. Pienaar et al. (2013:377) also reported a stronger relationship between basic mathematics, reading and writing literacy, VMI and visual perception abilities compared to the relationship that they found between these basic literacy skills, motor proficiency and motor coordination skills in school beginners. Skills that are assessed in the Grade 3 and 4 National Mathematical exam paper of South African children include, among others, calculation ability, knowledge of monetary and measurement units, figure patterns, factors, rounding off, fractions and identification of two- and three-dimensional shapes (ANA 2013). Various perceptual-motor skills serve as the underlying foundation for the successful execution of these skills. Perceptualmotor skills also underlie a variety of abilities like balance, laterality, spatial relationships, ocular motor control, crosslateral integration and body awareness (Auxter, Pyfer \& Huettig 2010). Cheatum and Hammond (2000:210) report that body awareness, laterality and direction play a significant role in the effective development of a body scheme which, furthermore, overflows into the development of spatial orientation. Furthermore, Gunderson et al. (2012:1238) and Van Lill (2011:22) report that good spatial orientation contributes to a better understanding of the number line because of improved knowledge of the linear spatial representation of figures. Richardson, Hunt and Richardson (2014:754) support the above opinions by indicating that spatial orientation is a significant predictor of mathematical achievement and that visual-spatial function serves as an 
additional predictor. Pieters et al. (2012:503) highlight that fine motor activities like sorting and visual-perceptual activities are needed to form an adequate mental representation of numerical concepts. Problems with VMI such as copying a figure can be affected by problems with visual perception for instance perceiving a circle or motor skills such as drawing lines or by integrating both (Sortor \& Kulp 2003). Furthermore, the study of Pieters et al. (2012:499, 503), on 7- to 9-year-old children with mathematical learning problems confirmed a relationship between visual perception and procedural calculation such as borrowing and transferring skills in maths. These findings confirm that visual perception and motor performance are closely linked (Gibson 1979) which, again, can influence performance in academic areas such as maths.

The results in Table 3 confirmed significantly poorer VMI, visual perception, motor coordination, manual dexterity, aiming-and-catching and balance skills in children with DCD which is also confirmed by other studies. The findings of Tsai et al. (2008:662) suggest a general immaturity of brain networks that support complex visual-spatial processing in children with DCD. A South African study on children with DCD confirmed relationships between ocular muscle control and moderate to serious DCD in 6- to 7-year-old children (Coetzee \& Pienaar 2011). Furthermore, Tsai et al. (2008:663) and Cheng et al. (2014:2177) reported poorer visual-perceptual skills, while Schoemaker et al. (2001:130) reported distinctive poorer visual closure and position in space perception skills in children with DCD compared to their typically developing peers. Our findings confirmed statistical as well as practically significant lower visual-perceptual skills in children with DCD which partially agree with the findings of Bonifacci (2004:164) who reported significant VMI differences $(p<0.014)$.

Our overall results are further confirmed by other studies that have reported that children with DCD display poorer academic abilities (Asonitou et al. 2012; Missiuna, Rivard \& Pollock 2004). Visual-motor integration and visual perception skills are indicated as role players in academic performance of children with DCD (Goldstand et al. 2005; Kulp 1999; Pieters et al. 2012; Van Hartingsveldt et al. 2014). Son and Meisels (2006:763) confirmed a relationship between visual-motor skills, gross motor skills and later reading, and especially mathematical achievement. Alloway and Temple (2007:483) states that learners with DCD have a poorer working memory which impacts directly on performance of literacy and numeracy skills. The child with DCD might also struggle with alignment and spacing of columns and numbers in mathematical questions which contribute to slower copying of figures or calculations from the board (Missiuna et al. 2004). Alloway and Temple (2007:483) reported that children with DCD performed poorly in literacy and numeracy assessments, while Sortor and Kulp (2003:761) found that motor coordination had a positive correlation with academic achievements. Morad et al. (2002:119) highlighted convergence skills, while Goldstand et al. (2005:383) add visual processing and visual functioning skills as role players in their academic achievement.
Tsai et al. (2008:663) report clinically significant deficits in different but interrelated visual-perceptual abilities in children with severe-DCD. Therefore, the present study confirms the above findings and confirms that visual perception correlates with DCD and academic achievement. A possible reason for this could be that there is a close link between VMI and motor skills. Problems with VMI, as seen in manual dexterity, could be affected by delays in visual perception and motor skills (Sortor \& Kulp 2003).

Impaired manual function is also reported in children with DCD (Bieber et al. 2016) and linked to poorer academic skills among them which also confirmed our findings regarding poorer manual dexterity in the DCD group. Luo et al. (2007) report significant relationships between fine motor skills and mathematics, stating that this relationship can be used to determine mathematical performance over time. In addition, Morales et al. (2011:411) report that fine motor skills have a stronger relationship with academic achievement than gross motor skills, and together with age, serves as a significant predictor of academic performance. Carlson et al. (2013:527) is of the opinion that the correlation between fine motor skills and academic achievement can also be ascribed to visualspatial integration and not necessarily to poor visual-motor coordination.

Furthermore, our results established that visual perception was the largest unique contributor of all the different perceptual and coordination predictor variables that were analysed in explaining academic achievement in children, irrespective of motor difficulties (Table 6). Shin, Park and Park (2009:622) report a close interplay between 9- and 13-year-old children's visual skills (especially accommodation) and their academic achievement, and state that binocular dysfunction has a negative effect on reading, mathematics, science and social science (Shin et al. 2009). However, motor coordination or hand control served to a lesser degree as contributors, especially in language-related learning areas (Table 6). Motor coordination and manual dexterity might reflect on the fine muscle control abilities of the group, as well-functioning fine motor muscles and control can influence the quality of handwriting tasks and writing speed (Malloy-Miller et al. 1995; Schwellnus et al. 2012). Tseng and Chow (2000:87) also confirmed a significant relationship between VMI skills and writing skills. It was also interesting to note that motor coordination (especially hand skills as assessed in the VMI-4) had a significant and bigger role to play in especially language learning areas. It may be that some similarities in underlying processes are shared, as handwriting skills are considered to be an integral part of language-expressive skills.

This research had limitations that need to be acknowledged. The DCD group $(n=47)$, which were identified from the overall group, was too small to be able to explore the differences and relationships that was investigated as extensive as what was intended. This group also included participants with moderate- and severe-DCD which could have influenced the strength of the associations that were established with 
academic performance. The participants also represent only one of nine regions in South Africa, influencing the generalisation of the results. Further studies, using a larger group and also representative of other parts of South Africa, is therefore recommended to confirm the above results. A fuller understanding of the contribution of the individual functional constructs of visual perception to academic performance is also still needed, as this relationship between academic achievement and underlying visual-perceptual-motor factors was only superficially investigated in this study. However, the strong link that was established between visual perceptual abilities and academic performance, necessitates more indepth research into the role of different but interrelated visualperceptual abilities in academic performance of children, especially those with DCD. The influences of factors such as poor socio-economic environments in this relationship should also be taken into account, as earlier studies indicated that it might account for or mediate relationships. The development and testing of interventions for young children with DCD with these deficits are also recommended.

\section{Conclusion and limitations}

Inferior VMI, visual perception, motor coordination, manual dexterity, aiming-and-catching and balance were found in children with DCD which showed statistical, practical and even clinical relevance. Visual perception made a significant contribution to academic performance of Grade 4 learners, irrespective of whether children had coordination problems such as DCD. Visual perception also correlated highly with mathematical achievement in children with DCD as well as in children without-DCD and therefore seems to play a significant role in the child's ability to understand the perceptual concepts that are needed to execute mathematical tasks effectively at the age of 10 years. However, coordination problems as a predictor of academic performance in typical children did not increase this difficulty, while manual dexterity did not only show a higher association to academic performance in children with DCD compared to typical children, but also in comparison with visual perception. It is assumed that if a young child's motor skills are atomised, they will need less energy to concentrate on performing these skills, especially fine motor tasks during the early school years and can instead concentrate on the academic tasks at hand. Gross motor control and visual perception develops during early childhood and both should be well developed by 10 years. As motor proficiency and visual perception are both developmental processes, exposure to relevant learning environments are thus necessary and educators and policymakers should hence provide adequate resources and opportunities to improve development of these skills. Intervention strategies should also be in place for those children who are at risk for academic failure based on these developmental deficits. Children should therefore be exposed to stimulating environments from a very young age where age-appropriate development of perceptual-motor skills can establish a firm foundation for later academic skills and especially mathematical achievement. Activities that can contribute to the improvement of visual perception abilities and mathematical achievement may include obstacle courses (spatial orientation), different animal walks (motor planning) and activities that include different colours, shapes and dimensions. Sufficient training and empowerment of teachers in the development of these skills are also essential. Our results highlight that all children, irrespective of whether they have motor coordination problems, need to participate in such development programs at a young age. Visual-motor integration, visual perception, motor coordination, manual dexterity, aiming-and-catching and balance skills of children with motor difficulties such as DCD should also receive remedial attention from an early age.

This study increased our understanding of the level of the relationship between perceptual and coordination factors in academic performance of children with DCD and also in typically developing children. Furthermore, it increases our understanding of the importance of these factors in academic performance of children.

\section{Acknowledgements}

The authors would like to acknowledge the Medical Research Council of South Africa, the National Research Foundation and South African Sugar Association for the grants that they provided to complete this research project. Sincere gratitude is also expressed to the 2013 Kinderkinetics Honours students of the North-West University for their assistance with the collection of data.

This publication has been developed through the Teaching and Learning Development Capacity Improvement Programme which is being implemented through a partnership between the Department of Higher Education and Training and the European Union.

\section{Competing interests}

The authors declare that they have no financial or personal relationships which may have inappropriately influenced them in writing this article.

\section{Authors' contributions}

E.d.W. wrote this article as part of her master's degree under A.E.P. and D.C.'s supervision.

\section{References}

Alloway, T. \& Temple, K., 2007, 'A comparison of working memory skills and learning in children with developmental coordination disorder and moderate learning difficulties', Applied Cognitive Psychology 21, 473-487. https://doi.org/10.1002/ acp.1284

American Psychiatric Association, 2013, Diagnostic and statistical manual of mental disorders, 5th edn., American Psychiatric Association, Washington, DC.

Asonitou, K., Koutsouki, D., Kourtessis, T. \& Charitou, S., 2012, 'Motor and cognitive performance differences between children with and without developmental coordination disorder (DCD)', Research in Developmental Disabilities 33, 9961005. https://doi.org/10.1016/j.ridd.2012.01.008

Auxter, D., Pyfer, J. \& Huettig, C., 2010, Principles and methods of adapted physical education and recreation, 11 th edn., McGraw-Hill, New York, NY.

Beery, K.E. \& Buktenica, N.A., 1997, The Beery-Buktenica developmental test of visual-motor integration: Administration, scoring and teaching manual, 4th edn., Modern Curriculum Press, Parsippany, NJ. 
Bezrukikh, M.M. \& Terebova, N.N., 2009, 'Characteristics of the development of visual perception in five-to-seven-year-old children', Human Physiology 35(6), 684-689. perception in five-to-seven-year-old children',
https://doi.org/10.1134/S0362119709060048

Bieber, E., Smits-Engelsman, B.C.M., Sgandurra, G., Cioni, G., Feys, H., Guzzetta, A et al., 2016, 'Manual function outcome measures in children with developmental coordination disorder (DCD): Systematic review', Research in Developmental Disabilities 55, 114-131. https://doi.org/10.1016/j.ridd.2016.03.009

Bonifacci, P., 2004, 'Children with low motor ability have lower motor-integration ability but unaffected perceptual skills', Human Movement Science 23, 157-168. https://doi.org/10.1016/j.humov.2004.08.002

Botha, P.N., 2013, 'A neurological, physiological and genetic orientation', in J.A. Kapp (ed.), Children with problems: An orthopedagogical perspective, pp. 201-255, Van Schaik, Pretoria.

Carlson, A.G., Rowe, E. \& Curby, T.W., 2013, 'Disentangling fine motor skills' relations to academic achievement: The relative contributors of visual-spatial integration and visual-motor coordination', The Journal of Genetic Psychology 174, 514-533. https://doi.org/10.1080/00221325.2012.717122

Cermak, S.A. \& Larkin, D., 2002, Developmental coordination disorder, Delmar Thompson Learning, Albany, NY.

Cheatum, B.A. \& Hammond, A.A., 2000, Physical activities for improving children's learning and behavior: A guide to sensory motor development, Human Kinetics, Champaign, IL.

Cheng, C.-H., Ju, Y.-Y., Chang, H.-W., Chen, C.-L., Pei, Y.-C., Tseng, K.C. et al., 2014, 'Motor impairments screened by the Movement Assessment Battery for Children-2 are related to the visual-perceptual deficits in children with Developmental are related to the visual-perceptual deficits in children with Developmental
Coordination Disorder', Research in Developmental Disabilities 35, 2172-2179. https://doi.org/10.1016/j.ridd.2014.05.009

Coetzee, D. \& Pienaar, A.E., 2011, 'The nature and scope of ocular muscle control among 7 to 8-year old children diagnosed with developmental coordination disorder (DCD)', African Journal for Physical, Health Education, Recreation and disorder (DCD), Africa
Dance 17, 887-901.

Cohen, J., 1988, Statistical power analysis for the behavioural sciences, 2nd edn., Erlbaum, Hillside, NJ.

Croce, R.V., Horvat, M. \& McCarthy, E., 2001, 'Reliability and concurrent validity of the movement assessment battery for children', Perceptual and Motor Skills 93 , 275-280. https://doi.org/10.2466/pms.2001.93.1.275

Diamond, A., 2000, 'Close interrelation of motor development and cognitive development and of the cerebellum and prefrontal cortex', Child Development 71 44-56.https://doi.org/10.1111/1467-8624.00117

Dwyer, G.M., Baur, L.A. \& Hardy, L.L., 2009, 'The challenge of understanding and assessing physical activity in preschool-age children: Thinking beyond the framework of intensity, duration and frequency of activity', Journal of Science and Medicine in Sport 12, 534-536. https://doi.org/10.1016/j.jsams.2008.10.005

Geary, D.C., Hamson, C.O. \& Hoard, M.K., 2000, 'Numerical and arithmetical cognition: A longitudinal study of process and concept deficits in children with learning disability', Journal of Experimental Child Psychology 77, 236-263. https://doi. org/10.1006/jecp.2000.2561

Gibson, J.J., 1979, The ecological approach to visual perception, Houghton Mifflin Boston, MA

Goldstand, S., Koslowe, K.C. \& Parush, S., 2005, 'Vision, visual-information processing, and academic performance among seventh-grade schoolchildren: A more significant relationship than we thought?', American Journal of Occupational significant relationship than we thought?', American Journal
Therapy 59, 377-389. https://doi.org/10.5014/ajot.59.4.377

Gunderson, E.A., Ramirez, G., Beilock, S.L. \& Levine, S.C., 2012, 'The relation between spatial skill and early number knowledge: The role of the linear number line', Developmental Psychology 48, 1229-1241. https://doi.org/10.1037/a0027433

Hartman, E., Houwen, S., Scherder, E.J.A. \& Visscher, C., 2010, 'On the relationship between motor performance and executive functioning in children with
intellectual abilities', Journal of Intellectual Disability Research 54, 468-477. https://doi.org/10.1111/j.1365-2788.2010.01284.x

Henderson, S.E., Sugden, D.A. \& Barnett, A.L., 2007, Movement assessment battery for Children-2 (MABC-2), 2nd edn., The Psychological Corporation, London.

Kulp, M.T., 1999, 'Relationship between visual motor integration skill and academic performance in kindergarten through third grade', Optometry and Vision Science 76, 159-163. https://doi.org/10.1097/00006324-199903000-00015

Kulp, M.T., Earley, M.J., Mitchell, G.L., Timmerman, L.M., Cara, S. \& Geiger, M.E., 2004 'Are visual perceptual skills related to mathematics ability in second through sixth grade children?', Focus on Learning Problems in Mathematics 26, 44-51.

Leonard, H.C., Bernardi, M., Hill, E.L. \& Henry, L.A., 2015, 'Executive functioning, motor difficulties and developmental coordination disorder', Developmental Neuropsychology 40, 201-215.https://doi.org/10.1080/87565641.2014.997933

Lepach, A.C., Pauls, F. \& Petermann, F., 2015, 'Executive functioning and visual working memory', Applied Neuropsychology: Adult 22, 100-107. https://doi.org /10.1080/23279095.2013.860603

Lingam, R., Hunt, L., Goulding, J., Jongmans, M. \& Emond, A., 2009, 'Prevalence of developmental coordination disorder using the DSM-IV at 7 years of age: A UL population-based study', Journal of the American Academy of Paediatrics 123, 693-699. https://doi.org/10.1542/peds.2008-1770

Lopes, L., Santos, R., Pereira, B. \& Lopes, V.P., 2013, 'Associations between gross motor coordination and academic achievement in elementary school children', Human Movement Science 32, 9-20. https://doi.org/10.1016/j.humov.2012.05.005
Luo, Z., Jose, P.E., Huntsinger, C.S. \& Pigott, T.D., 2007, 'Fine motor skills and mathematical achievement in East Asian American and European American kindergartners and first graders', British Journal of Developmental Psychology 25 , 595-614. https://doi.org/10.1348/026151007X185329

Malloy-Miller, T., Polatajko, H. \& Anstett, B., 1995, 'Handwriting error patterns of children with mild motor difficulties', Canadian Journal of Occupational Therapy 62, 258-267. https://doi.org/10.1177/000841749506200505

Memisevic, H. \& Sinanovic, O., 2013, 'Executive functions as predictors of visual motor integration in children with intellectual disability', Perceptual and Motor Skills 117, 913-922.https://doi.org/10.2466/15.25.PMS.117x25z4

Michel, E., Roethlisberger, M., Neuenschwander, R. \& Roebers, C.M., 2011 'Development of cognitive skills in children with motor coordination impairments at 12-month follow-up', Child Neuropsychology 17, 151-172. https://doi.org/10.1 080/09297049.2010.525501

Missiuna, C., Rivard, L. \& Pollock, N., 2004, 'They're bright but can't write: Developmental coordination disorder in school aged children', Teaching Exceptional Children Plus 1(1), Article 3.

Morad, Y., Lederman, R., Avni, I., Atzmon, D., Azoulay, E. \& Segal, O., 2002, 'Correlating between reading skills and different measurements of convergence amplitude', Current Eye Research 25, 117-121. https://doi.org/10.1076/ceyr.25.2.117.10155

Morales, J., Gonzáles, L-M., Guerra, M., Virgili, C. \& Unnithan, V., 2011, 'Physical activity, perceptual-motor performance, and academic learning in 9-to-16-years old school children', International Journal of Sport Psychology 42, 401-415.

Pauw, K., 2005, 'Profile of the North West Province: Demographics, poverty, inequality and unemployment', Provided Project Background Paper 1, 1-9.

Piek, J.P., Dawson, L., Smith, L.M. \& Gasson, N., 2008, 'The role of early fine and gross motor development on later motor and cognitive ability', Human Movement Science 27, 668-681. https://doi.org/10.1016/j.humov.2007.11.002

Pienaar, A.E., Barhorst, R. \& Twisk, J.W.R., 2013, 'Relationships between academic performance, SES school type and perceptual motor skills in first grade South African learners: NW-CHILD study', Child: Care, Health and Development 40, 370378. https://doi.org/10.1111/cch.12059

Pieters, S., Desoete, A., Roeyers, H., Vanderswalmen, R. \& Van Waelvelde, H., 2012, 'Behind mathematical learning disabilities: What about visual perception and motor skills?', Learning and Individual Differences 22, 498-504. https://doi. org/10.1016/j.lindif.2012.03.014

Purcell, C., Wann, J.P., Wilmut, K. \& Poulter, D., 2012, 'Reduced looming sensitivity in primary school children with developmental co-ordination disorder', Developmental Science 15, 299-306. https://doi.org/10.1111/j.1467-7687.2011. 01123.x

Richardson, M., Hunt, T.E \& Richardson, C., 2014, 'Children's construction task performance and spatial ability: Controlling task complexity and predicting mathematics performance', Perceptual and Motor Skills: Learning and Memory 119, 741-757. https://doi.org/10.2466/22.24.PMS.119c28z8

Riethmuller, A.M., Jones, R. \& Okely, A.D., 2009, 'Efficacy of interventions to improve motor development in young children: A systematic review', Pediatrics 124 e782-e792. https://doi.org/10.1542/peds.2009-0333

Roebers, C.M. \& Kauer, M., 2009, 'Motor and cognitive control in a normative sample of 7-year-olds', Developmental Science 12, 175-181. https://doi.org/10.1111/ j.1467-7687.2008.00755.x

Schoemaker, M.M., Van der Wees, M., Flapper, B., Verheij-Jansen, N., ScholtenJaegers, S. \& Geuze, R.H., 2001, 'Perceptual skills of children with developmental coordination disorder', Human Movement Science 20, 111-133.https://doi. org/10.1016/S0167-9457(01)00031-8

Schurink, J., Hartman, E., Scherder, E.J.A., Houwem, S. \& Visscher, C., 2012, 'Relationship between motor and executive functioning in school-age children with pervasive developmental disorder not otherwise specified', Research in Autism Spectrum Disorder 6, 726-732.https://doi.org/10.1016/j.rasd.2011.10.013

Schwellnus, H., Carnahan, H., Kushki, A., Polatajko, H., Missiuna, C. \& Chau, T., 2012, 'Effect of pencil grasp on the speed and legibility of handwriting after a 10-minute copy task in grade 4 children', Australian Occupational Therapy Journal 59, 180187. https://doi.org/10.1111/j.1440-1630.2012.01014.x

Shin, H.S., Park, S.C. \& Park, C.M., 2009, 'Relationship between accommodative and vergence dysfunctions and academic achievement for primary school children' Ophthalmic and Physiological Optics 29, 615-624. https://doi.org/10.1111/ j.1475-1313.2009.00684.x

Son, S.-H. \& Meisels, S.J., 2006, 'The relationship of young children's motor skills to later reading and math achievement', Merill-Parmer Quarterly 52, 755-778. https://doi.org/10.1353/mpq.2006.0033

Sortor, J.M. \& Kulp, M.T., 2003, 'Are the results of the Beery-Buktenica developmental test of visual-motor integration and its subtest related to achievement test scores?' Optometry and Vision Science 80, 758-763. https://doi.org/10.1097/00006324200311000-00013

South Africa, Annual National Assessment, 2013, 'Department of Education', viewed 15 August 2014, from http://www.education.gov.za/2013ANAtestsandmemos/ tabid/600/Default.aspx

South Africa, Curriculum and Assessment Policy Statement, 2014, 'Department of Education', viewed 31 May 2016, from http://www.education.gov.za/Curriculum/ CurriculumAssessmentPolicyStatements(CAPS)/CAPSIntermediate.aspx

South Africa, Department of Basic Education, 2014, 'Education statistics in South Africa 2013', North West, Department of Basic Education, Pretoria. 
South Africa, Department of Education, 2016, 'Annual National Assessments', viewed 15 August 2014, from http://www.education.gov.za/Curriculum/ AnnualNationalAssessments(ANA).aspx

StatSoft, 2015, Statistica for Windows: General conventions \& statistics, Statsoft, Tilsa, OK.

Tan, S.K., Parker, H.E. \& Larkin, D., 2001, 'Concurrent validity of motor tests used to identify children with motor impairment', Adapted Physical Activity Quarterly 18 , 168-182. https://doi.org/10.1123/apaq.18.2.168

Thorell, L.B., Veleiro, A., Siu, A.F.Y. \& Mohammadi, H., 2013, 'Examining the relation between the ratings of executive functioning and academic achievement: Findings from a cross-cultural study', Child Neuropsychology 19, 630-638.https://doi.org/1 $0.1080 / 09297049.2012 .727792$

Tsai, C.L., Wilson, P.H. \& Wu, S.K., 2008, 'Role of visual-perceptual skills (non-motor) in children with developmental coordination disorder', Human Movement Science 27, 679-664. https://doi.org/10.1016/j.humov.2007.10.002
Tseng, M.H. \& Chow, S.M.K., 2000, 'Perceptual-motor function of school-age children with slow handwriting speed', The American Journal of Occupational Therapy 54 83-88. https://doi.org/10.5014/ajot.54.1.83

Van Hartingsveldt, M., J., Cup, E.H.C., De Groot, I.J.M. \& Nijhuis-van der Sanden M.W.G., 2014 'Writing Readiness Inventory Tool in Context (WRITIC): Reliability and convergent validity', Australian Occupational Therapy Journal 61, 102-109. https://doi.org/10.1111/1440-1630.12082

Van Lill, J., 2011, Jou kind kan wiskunde doen, 1st edn., Metz Press, Bellville, South Africa.

Westendorp, M., Hartman, E., Houwen, S., Smith, J. \& Visscher, C., 2011, 'The relationship between gross motor skills and academic achievement in children with learning disabilities', Research in Developmental Disabilities 32, 2773-2779. https://doi.org/10.1016/j.ridd.2011.05.032

Zhu, S., Tang, G. \& Shi, J., 2012, 'Cross-sectional study of executive functioning in children with developmental coordination disorders', Shanghai Archives of Psychiatry 24, 217-221. 